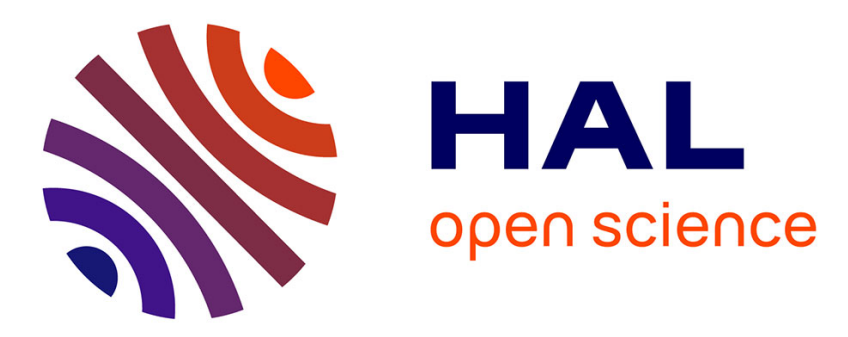

\title{
Disparities in HIV-1 transmitted drug resistance detected by ultradeep sequencing between men who have sex with men and heterosexual populations
}

Eve Todesco, C. Charpentier, M. Bertine, M. Wirden, A. Storto, N. Desire, M. Grude, T. Nguyen, S. Sayon, Y. Yazdanpanah, et al.

\section{To cite this version:}

Eve Todesco, C. Charpentier, M. Bertine, M. Wirden, A. Storto, et al.. Disparities in HIV-1 transmitted drug resistance detected by ultradeep sequencing between men who have sex with men and heterosexual populations. HIV Medicine, 2017, 10.1111/hiv.12508 . hal-01518302

\section{HAL Id: hal-01518302 \\ https://hal.sorbonne-universite.fr/hal-01518302}

Submitted on 4 May 2017

HAL is a multi-disciplinary open access archive for the deposit and dissemination of scientific research documents, whether they are published or not. The documents may come from teaching and research institutions in France or abroad, or from public or private research centers.
L'archive ouverte pluridisciplinaire HAL, est destinée au dépôt et à la diffusion de documents scientifiques de niveau recherche, publiés ou non, émanant des établissements d'enseignement et de recherche français ou étrangers, des laboratoires publics ou privés. 
1 Disparities in HIV-1 Transmitted Drug Resistance detected by

2 UltraDeep Sequencing among Men having Sex with Men and

3 Heterosexual Populations

4 Running head: HIV-1Transmitted Drug Resistance

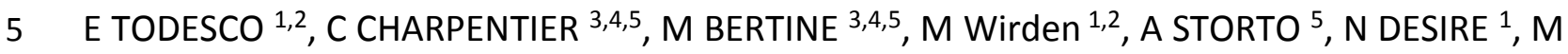

6 GRUDE $^{1}$, T NGUYEN ${ }^{1,2}$, S SAYON ${ }^{1,2}$, Y YAZDANPANAH ${ }^{3,4,6}$, C KATLAMA $^{1,7}$, D DESCAMPS ${ }^{3,4,5}$,

$7 \quad$ V CALVEZ $^{1,2}$, AG MARCELIN ${ }^{1,2}$

8 Institional affiliations:

9

${ }^{1}$ Sorbonne Universités, UPMC Univ Paris 06, INSERM, Institut Pierre Louis d'épidémiologie et de Santé Publique (IPLESP UMRS 1136), F75013, Paris, France, ${ }^{2}$ Department of Virology, Hôpital Pitié-Salpêtrière, AP-HP, F75013, Paris, France, ${ }^{3}$ INSERM, IAME, UMR 1137, Sorbonne Paris Cité, F-75018 Paris, France, ${ }^{4}$ Univ Paris Diderot, IAME, UMR 1137, F-75018 Paris, France, ${ }^{5}$ AP-HP, Hôpital Bichat-Claude Bernard, Laboratoire de Virologie, F-75018, Paris, France, ${ }^{6}$ AP-HP, Hôpital Bichat-Claude Bernard, Department of Infectious Diseases, F75018 Paris, France, ${ }^{7}$ Department of Infectious Diseases, Hôpital Pitié-Salpêtrière, AP-HP, F75013, Paris, France

Word counts of the abstract: 169 words

Word counts of the text: 1463 words

\section{Corresponding author:}

Eve Todesco, Department of Virology, Bât CERVI, Hôpital Pitié-Salpêtrière, 83 Bd de I'Hôpital, 75013 Paris, France. Email: eve.todesco@aphp.fr. Fax: 331 42177411. Phone: 33142177426 
23 Keywords: HIV; Deep Sequencing; Minority resistant variants; Transmitted Drug Resistance. 


\section{Abstract}

\section{Objectives}

Transmitted Drug Resistance (TDR) can impair first-line antiretroviral therapy response. It has been shown by Sanger sequencing that TDR was more common among Men having Sex with Men (MSM) in treatment-naive patients chronically infected with HIV type 1 (HIV-1). We aimed to compare the presence of TDR mutations between two groups of HIV-1 transmission.

\section{Methods}

We studied, by Sanger Sequencing and UltraDeep Sequencing (UDS), the presence of resistance mutations, both in majority $(>20 \%)$ and in minority $(1-20 \%)$ proportions, among 70 treatment-naive MSM and 70 treatment-naive heterosexual patients recently screened positive for HIV-1.

\section{Results}

Between the two groups, global prevalence of TDR was not significantly different either by Sanger or by UDS. Nevertheless, a higher frequency of nucleoside reverse transcriptase inhibitors-TDR was observed among heterosexual patients $(p=0.04)$. There was also a trend for a higher frequency of TDR among MSM infected with HIV-1 subtype B compared to MSM infected with HIV-1 subtype non-B ( $p=0.06)$.

\section{Conclusions}

UDS allows sensitive monitoring of TDR, and highlights some disparities between groups of transmission. 


\section{INTRODUCTION}

Transmitted Drug Resistance (TDR) detection can impair first-line antiretroviral therapy response. Indeed, the presence of TDR-mutations can conduct to a higher risk of virological failure if the affected drugs are introduced [1]. The surveillance of HIV type 1 (HIV-1) TDR is widely recommended and it has been shown that TDR was more common among Men having Sex with Men (MSM) and among patients infected with subtype B virus in the $2010 / 2011$ French survey study conducted in antiretroviral-naïve chronically HIV-1infected patients by standard sequencing techniques [2]. Standard sequencing detects viral populations accounting for more than $15-20 \%$ of viral population. However, HIV-1 minority resistant variants can be a source of virological failure: it was mainly shown for first line regimens based on first generation Non Nucleoside Reverse Transcriptase Inhibitors (NNRTI) $[3,4]$. The next generation sequencing technologies are able to detect these minority variants. Nevertheless, few data are available on presence of minority TDR variants in different groups of HIV transmission, treatment-naive patients [5]. The use of UltraDeep Sequencing (UDS) could evidence larger difference of TDR between groups of transmission than Sanger sequencing does.

The aim of the study was to compare the presence of TDR mutations, both in majority (>20\%) and in minority (1-20\%) proportions, between treatment-naive MSM and treatmentnaive heterosexual HIV-1 chronically infected patients.

\section{METHODS}

Patients. The study enrolled 70 treatment-naïve heterosexual patients and 70 treatmentnaïve MSM recently diagnosed for HIV-1. We performed Sanger Sequencing ( $n=140 ;$ Reverse Transcriptase gene (RT) and Protease gene (PR)) and UDS ( $n=70$ RT and $n=70$ PR sequences among MSM group; $n=54$ RT and $n=67$ PR sequences among heterosexual group). Patients 
were followed by Department of Infectious Diseases of Pitié-Salpêtrière and Bichat Claude Bernard hospitals (Paris, France). Informations were obtained from the existing electronic database or medical record. Patients were informed that their demographic and clinical data will be recorded during their follow up and could be used for retrospective studies and gave their consent. This study was approved by the Agence Nationale de Recherches sur le SIDA et les hépatites virales (ANRS) AC11 Ethics Committee.

Sanger sequencing. The first sample of plasma positive for HIV-1 was used for performing genotypic resistance test. RT and PR genotypic analysis was conducted according to the ANRS consensus method [6]. PR and RT mutations were identified using the consensus statement of the list for the TDR genotypic surveillance. [7] Additional interpretations were performed with the International AIDS Society (IAS) list (figure) and the last version of ANRS algorithm (www.hivfrenchresistance.org). Any sequences found to have a mixture of wild type and mutant amino acid residues at single positions were considered to have the mutant.

The subtype determination was performed using the HIV Module of SmartGene (SmartGene, Zug, Switzerland) whose methodology is based on Basic Local Alignment Search Tool (BLAST).

UDS. The steps until pyrosequencing on GS Junior (Roche $454^{\circledR}$ Life Sciences, Branford, CT, United States) were previously described [8]. Primers used are available on hiv.frenchresistance.org. Pyrosequencing was performed according to manufacturer recommendations [9]. GS Amplicon Variant Analyzer (Roche $454^{\circledR}$ Life Sciences, Branford, $\mathrm{CT}$, United States) was used to analyze the UDS results. Alignments were checked. 
Statistical Analysis. To compare MSM and heterosexual populations baseline characteristics, Chi 2 and Mann-Whitney tests were used for categorical (subtype) and continuous variables (age, viral load, CD4 cells count), respectively.

Global prevalence and prevalence of TDR mutations by antiretroviral classes were compared by a Chi 2 test between the two groups.

\section{RESULTS}

An average of 5198 reads per nucleotide position was amplified and the average error rates in controls (cellular clone 8E5) were 0.0012 and 0.0032 for RT and PR, respectively. These results allowed for accurate detection of variants down to $1 \%[10,11]$.

Characteristics of patients are as follows: the median age was 36.3 years among the 70 MSM patients and 35.4 years among the 70 heterosexual patients (60\% female), without significant difference between the two populations. Sixty percent of the patients were infected by HIV-1 subtype B among the MSM group whereas $94 \%$ were infected by HIV-1 subtype non-B among the heterosexual group. Among the MSM patients, median viral load (VL) was $4.9 \log _{10}$ copies/mL (IQR=4.4-5.4) and median CD4 cell count was $498 / \mathrm{mm}^{3}$ (IQR=347-585). Among the heterosexual patients, median VL was $4.9 \log _{10}$ copies $/ \mathrm{mm}^{3}$ (IQR=4.3-5.3) and median CD4 cell count was 348/mm (IQR=208-497). The levels of HIV-1 VL were similar between the two groups, but median CD4 cell count was higher among MSM than among heterosexual patients $(p=0.0016)$.

Global prevalence of TDR and prevalence by drug classes are presented in Table 1. A total concordance was found between Sanger sequencing and UDS for all mutations detected on bulk. 
Sanger sequencing detected two Nucleoside Reverse Transcriptase Inhibitors (NRTI)-TDR mutations in virus genome of one MSM patient (M41L and T215C) and one in virus genome of three heterosexual patients (M41L or T215E or M184I/V); one NNRTI-TDR mutation was detected in virus genome of two MSM patients (K103N) and one in virus genome of three heterosexual patients (K103N or Y181I or Y188L) and one Protease Inhibitors (PI)-TDR mutation was detected in virus genome of one heterosexual patient (I85V).

Within each group, we retrieved a higher prevalence of TDR mutations when UDS was performed: prevalence of TDR was $18.6 \%(95 \% \mathrm{Cl}=9.4 \%-27.7 \%)$ with UDS versus $4.3 \%$ (95\% $\mathrm{Cl}=0.0 \%-9.1 \%)$ with Sanger Sequencing among $\mathrm{MSM}$ and $22.8 \%$ (95\% $\mathrm{Cl}=12.7 \%-33.0 \%)$ with UDS versus $7.1 \%(95 \% \mathrm{Cl}=0.9 \%-13.4 \%)$ with Sanger Sequencing among heterosexual population.

Among the MSM, the increased TDR detected by UDS was observed especially for NNRTI and PI (10.0\% versus $2.9 \%$ by Sanger sequencing and $7.1 \%$ versus $0.0 \%$ by Sanger sequencing, respectively) while it was mainly for $\mathrm{NRTI}$ and PI among the heterosexual patients (14.8\% versus $4.3 \%$ by Sanger sequencing and $10.4 \%$ versus $1.4 \%$ by Sanger sequencing, respectively).

The rate of TDR mutations only detected by UDS was low: between $1.1 \%$ and $4.8 \%$ for NRTI, $1.1 \%$ and $1.5 \%$ for NNRTI and $1.1 \%$ and $7.0 \%$ for PI (Figure 1 ).

Between the two groups, global prevalence of TDR was not significantly different either by Sanger or by UDS. Nevertheless, a higher frequency of NRTI-TDR was observed among heterosexual patients than among MSM ( $14.8 \%$ versus $4.3 \%$, respectively; $p=0.04)$.

We also retrieved a trend for a higher frequency of TDR among MSM patients infected with HIV-1 subtype B compared to MSM patients infected with HIV-1 subtype non-B (26.2\% ( $n=11 / 42)$ versus $7.1 \%(n=2 / 28)$ with UDS $(p=0.06)$, data not shown). 
140 In addition, some resistance mutations, not considered in the list for TDR genotypic

141 surveillance, but considered as major in some genotypic algorithms, were identified as

142 minority variants. For instance, three K65E mutations were detected by UDS. With the last

143 version of ANRS algorithm, the prevalence of resistance to the recommended drugs

144 (European AIDS Clinical Society EACS) detected by UDS for NRTI, NNRTI and IP were 2.9\%,

$14512.8 \%$ and $7.1 \%$ among MSM patients and $11.1 \%, 5.6 \%$ and $11.9 \%$ among heterosexual

146 patients, respectively.

\section{DISCUSSION}

148 Higher prevalence of TDR was observed in antiretroviral-naive chronically HIV-1-infected

149 MSM and heterosexual populations when UDS was used compared to population

150 sequencing. Indeed, these powerful techniques could improve the detection of HIV-1-TDR.

151 In the present study, UDS allowed to detect a higher frequency of NRTI-TDR among

152 heterosexual population than among MSM patients, whereas based on the results of CD4

153 cell count, the date of transmission seems to be older in the heterosexual population.

154 Usually, the more time goes by and the less TDR are detected. However, most thymidine

155 analogue mutations were found to be highly stable without selection pressure. It has been

156 shown that NNRTI and PI mutations were, globally, less persistent than NRTI mutations,

157 maybe because of a negative impact on viral fitness [11,12].

158 Otherwise, UDS evidenced a higher frequency of TDR in subtype B versus subtype non-B 159 viruses among MSM patients. This is consistent with what has been previously shown by 160 Sanger sequencing in the Odyssee study on antiretroviral-naive chronically HIV infected 161 patients and in the study on French patients diagnosed at the time of primary HIV-1 162 infection $[2,13]$. 
163 We obviously need further investigations for NRTI, second generation NNRTI and PI-based 164 regimen, as the impact of minority TDR mutations on first generation NNRTI is already well 165 known $[3,4]$. Furthermore, minority TDR mutations on integrase strand transfer inhibitors 166 have not been studied in this work. As few data are available on this subject and still 167 controversial, more studies are needed [14,15]. Nevertheless, an increase of TDR is 168 predictable for this therapeutic class with the extensive use of these drugs and should be 169 monitored in the future.

170 In conclusion, UDS allows sensitive monitoring of TDR, and is able to evidence some 171 disparities of TDR between HIV groups of transmission. In the present study, next generation 172 sequencing technologies probably detect minority resistant variants that are disappearing.

173 The impact of these minority TDR mutations for certain therapeutic classes and in particular 174 for the more recent drugs is unknown and should be further evaluated. 
176 Ackowledgments:

177 We thank Géraldine Lemallier and Philippe Grange for their technical assistance, and ROCHE 178 DIAGNOSTICS FRANCE.

179 Conflicts of interest: All authors declare that they have no conflicts of interest.

180 Funding: This work was supported by the Agence Nationale de Recherches sur le SIDA et les 181 hépatites virales (ANRS).

182 
1. Wittkop L, Günthard HF, de Wolf F, et al. Effect of transmitted drug resistance on virological and immunological response to initial combination antiretroviral therapy for HIV (EuroCoord-CHAIN joint project): a European multicohort study. Lancet Infect Dis 2011; 11(5):363-71.

2. Descamps D, Assoumou L, Chaix M-L, et al. National sentinel surveillance of transmitted drug resistance in antiretroviral-naive chronically HIV-infected patients in France over a decade: 2001-2011. J Antimicrob Chemother 2013; 68(11):2626-31.

3. Li JZ, Paredes R, Ribaudo HJ, et al. Low-frequency hiv-1 drug resistance mutations and risk of nnrti-based antiretroviral treatment failure: A systematic review and pooled analysis. JAMA. 2011; 305(13):1327-35.

4. Cozzi-Lepri A, Noguera-Julian M, Giallonardo FD, et al. Low-frequency drug-resistant HIV-1 and risk of virological failure to first-line NNRTI-based ART: a multicohort European case-control study using centralized ultrasensitive 454 pyrosequencing. J Antimicrob Chemother 2015;

5. Cunningham E, Bibby D, Lythgow K, et al. Enhanced surveillance of HIV-1 transmitted drug resistance and transmission clusters in recently infected UK MSM. International Workshop on Antiviral Drug Resistance 2014. Berlin, Germany, June 2014.

6. Descamps D, Delaugerre C, Masquelier B, et al. Repeated HIV-1 resistance genotyping external quality assessments improve virology laboratory performance. J Med Virol 2006; 78(2):153-60.

7. Bennett $\mathrm{DE}$, Camacho RJ, Otelea $\mathrm{D}$, et al. Drug resistance mutations for surveillance of transmitted HIV-1 drug-resistance: 2009 update. PloS One 2009; 4(3): e4724. 
8. Todesco E, Rodriguez C, Morand-Joubert L, et al. Improved detection of resistance at failure to a tenofovir, emtricitabine and efavirenz regimen by ultradeep sequencing. I Antimicrob Chemother 2015; 70(5):1503-6.

9. Daigle D, Simen BB, Pochart P. High-throughput sequencing of PCR products tagged with universal primers using 454 life sciences systems. Curr Protoc Mol Biol 2011; 96: 7.5.1-7.5.14.

10. Wang C, Mitsuya Y, Gharizadeh B, Ronaghi M, Shafer RW. Characterization of mutation spectra with ultra-deep pyrosequencing: application to HIV-1 drug resistance. Genome Res 2007; 17(8):1195-201.

11. Castro H, Pillay D, Cane P, et al. Persistence of HIV-1 transmitted drug resistance mutations. J Infect Dis 2013; 208(9):1459-63.

12. Wirden $M$, Delaugerre $C$, Marcelin AG, et al. Comparison of the dynamics of resistanceassociated mutations to nucleoside reverse transcriptase inhibitors, nonnucleoside reverse transcriptase inhibitors, and protease inhibitors after cessation of antiretroviral combination therapy. Antimicrob Agents Chemother 2004; 48(2):644-7.

13. Frange $P$, Assoumou $L$, Descamps $D$, et al. HIV-1 subtype B-infected MSM may have driven the spread of transmitted resistant strains in France in 2007-12: impact on susceptibility to first-line strategies. J Antimicrob Chemother 2015; 70(7):2084-9.

14. Charpentier C, Lee GQ, Rodriguez C, et al. Highly frequent HIV-1 minority resistant variants at baseline of the ANRS 139 TRIO trial had a limited impact on virological response. J Antimicrob Chemother 2015; 70(7):2090-6.

15. Armenia D, Vandenbroucke I, Fabeni L, et al. Study of genotypic and phenotypic HIV-1 dynamics of integrase mutations during raltegravir treatment: a refined analysis by ultra-deep 454 pyrosequencing. J Infect Dis 2012; 205(4):557-67. 
Table 1: Global prevalence of Transmitted Drug Resistance and by drug classes among the two groups: MSM and heterosexual patients.

\begin{tabular}{|c|c|c|c|c|c|c|}
\hline & \multicolumn{3}{|c|}{ Sanger sequencing } & \multicolumn{3}{|c|}{ UltraDeep sequencing } \\
\hline & $\begin{array}{l}\text { MSM } \\
n=70\end{array}$ & $\begin{array}{l}\text { Heterosexual } \\
\text { population } \\
n=70\end{array}$ & p value & $\begin{array}{l}\text { MSM } \\
n=70\end{array}$ & $\begin{array}{l}\text { Heterosexual } \\
\text { population } \\
\text { RT } n=54 \\
\text { Protease } n=67\end{array}$ & $\begin{array}{l}\mathrm{p} \\
\text { value }\end{array}$ \\
\hline $\begin{array}{l}\text { Global prevalence of } \\
\text { TDR } \\
{[95 \% \mathrm{Cl}]}\end{array}$ & $\begin{array}{l}n=3 \\
4.3 \% \\
{[0.0 \%-9.1 \%]}\end{array}$ & $\begin{array}{l}n=5 \\
7.1 \% \\
{[0.9 \%-13.4 \%]}\end{array}$ & 0.47 & $\begin{array}{l}n=13 \\
18.6 \% \\
{[9.4 \%-27.7 \%]}\end{array}$ & $\begin{array}{l}n=16 \\
22.8 \% \\
{[12.7 \%-33.0 \%]}\end{array}$ & 0.53 \\
\hline $\begin{array}{l}\text { Prevalence of NRTI- } \\
\text { TDR } \\
{[95 \% \mathrm{CI}]}\end{array}$ & $\begin{array}{l}n=1 \\
1.4 \% \\
{[0.0 \%-4.2 \%]}\end{array}$ & $\begin{array}{l}n=3 \\
4.3 \% \\
{[0.0 \%-9.2 \%]}\end{array}$ & 0.31 & $\begin{array}{l}n=3 \\
4.3 \% \\
{[0.0 \%-9.1 \%]}\end{array}$ & $\begin{array}{l}\mathrm{n}=8 \\
14.8 \% \\
{[5.3 \%-24.4 \%]}\end{array}$ & 0.04 \\
\hline $\begin{array}{l}\text { Prevalence of NNRTI- } \\
\text { TDR } \\
{[95 \% \mathrm{Cl}]}\end{array}$ & $\begin{array}{l}n=2 \\
2.9 \% \\
{[0.0 \%-6.8 \%]}\end{array}$ & $\begin{array}{l}n=3 \\
4.3 \% \\
{[0.0 \%-9.2 \%]}\end{array}$ & 0.65 & $\begin{array}{l}n=7 \\
10.0 \% \\
{[2.9 \%-17.1 \%]}\end{array}$ & $\begin{array}{l}n=4 \\
7.4 \% \\
{[0.4 \%-14.5 \%]}\end{array}$ & 0.61 \\
\hline $\begin{array}{l}\text { Prevalence of PI-TDR } \\
{[95 \% \mathrm{Cl}]}\end{array}$ & $\begin{array}{l}n=0 \\
0.0 \%\end{array}$ & $\begin{array}{l}n=1 \\
1.4 \% \\
{[0.0 \%-4.3 \%]}\end{array}$ & 0.32 & $\begin{array}{l}n=5 \\
7.1 \% \\
{[1.1 \%-13.2 \%]}\end{array}$ & $\begin{array}{l}n=7 \\
10.4 \% \\
{[3.1 \%-17.8 \%]}\end{array}$ & 0.49 \\
\hline
\end{tabular}

CI: Confidence Interval; MSM: Men Men having Sex with Men; NRTI: Nucleoside Reverse Transcriptase Inhibitors; NNRTI: Non NRTI; PI: Protease Inhibitors; TDR: Transmitted Drug Resistance 
Mutations only detected by UltraDeep Sequencing a

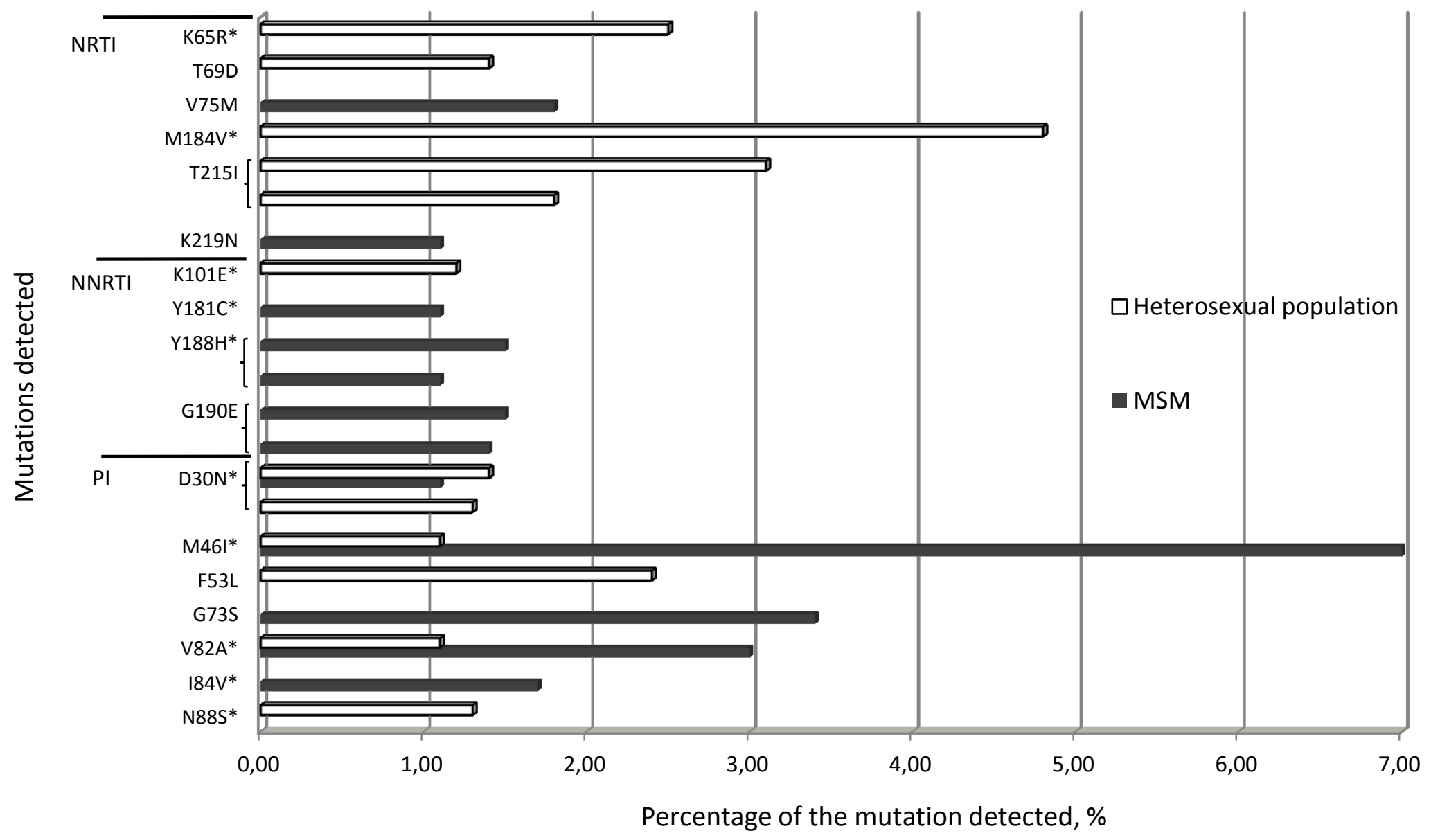

${ }^{a}$ : Each bar represents one patient; ${ }^{*}$ Major IAS drug resistance mutations

MSM: Men having Sex with Men; NRTI: Nucleoside Reverse Transcriptase Inhibitors; NNRTI: Non NRTI; PI: Protease

Inhibitors; UDS: UltraDeep Sequencing 